\title{
Changes to Journal Ethics Policy to Address Instances of Plagiarism
}

\author{
Ryan M. Deacon ${ }^{1}$
}

Published online: 28 January 2016

(C) Springer Science+Business Media New York and ASM International 2016

Since its inception, each issue of Metallography, Microstructure, and Analysis has included the journal's statement on ethics, which outlines the behavior that is expected of authors who submit their manuscripts to the journal. Topics covered by the policy include image manipulation, disclosing financial interests, and ensuring that proper credit is given to authors whose published works are referenced in a paper. The Ethics Policy also states that "Any attempted duplication of previously published material, or plagiarism from the published or unpublished work of others will be met with severe reprimand."

Recognizing the consequences that instances of plagiarism in scholarly publishing have for both the authors(s) and the journal to which it was submitted, the editorial staff of MMA has expanded this single sentence into a formal policy on plagiarism. The policy codifies the existing practices of the journal regarding plagiarism into a comprehensive statement that will provide authors with a clear understanding of the journal's expectations and potential actions in the event of plagiarism.

The policy is included in this issue and is posted on the journal's website.

Every case of plagiarism is unique, and can range from an author simply lacking sufficient knowledge of proper citation practices, to deceitful and dishonest attempts to present the work of another as one's own. In light of this fact, the policy practiced by the journal provides flexibility

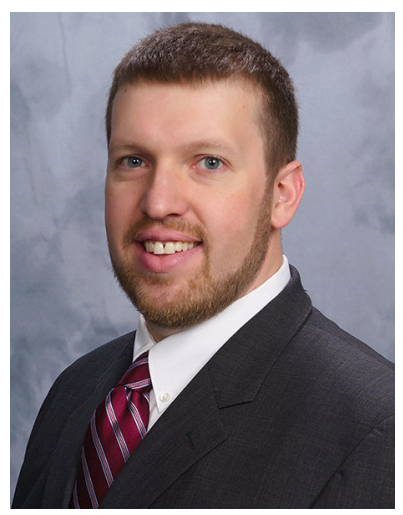

in addressing instances of plagiarism. The intent is to ensure the fair treatment of the author(s) while at the same time protecting the integrity of the scholarly publication process.

MMA's policy was largely adopted from the policy of the Journal of Thermal Spray Technology (JTST), which has had a comprehensive statement on plagiarism for several years. In addition, guidance from Springer and from the Committee on Publication Ethics (COPE) was integral in forming the basis for MMA's policy. The editorial staff of MMA would like to thank JTST, Springer, and COPE for their assistance in this process. Questions about the plagiarism policy for MMA can be directed to the journal Editor at ryan.deacon@asminternational.org.

Ryan M. Deacon

ryan.deacon@asminternational.org

1 DuPont Engineering Research and Technology, DuPont Co., Experimental Station, E302/117D, P.O. Box 80302, Wilmington, DE 19880-0302, USA 